\title{
The ovipositing female of Ooencyrtus telenomicida relies on physiological mechanisms to mediate intrinsic competition with Trissolcus basalis
}

\author{
Antonino Cusumano ${ }^{1}$, Ezio Peri ${ }^{1 *}$, S. Bradleigh Vinson ${ }^{2}$ \& Stefano Colazza ${ }^{1}$ \\ ${ }^{1}$ Dipartimento DEMETRA, Università degli Studi di Palermo, viale delle Scienze, Palermo 90128, Italy, and ${ }^{2}$ Department of \\ Entomology, ERL 2475, Texas A\&M University, College Station, TX 77843, USA
}

Accepted: 26 January 2012

Key words: egg parasitoid, physiological suppression, melanization, stink bug, parasitoid-parasitoid interaction, host-parasitoid interaction, Hymenoptera, Scelionidae, Encyrtidae, Heteroptera, Pentatomidae

\begin{abstract}
Ongoing studies by our group showed that the outcome of the intrinsic competition between two solitary egg parasitoids, Trissolcus basalis (Wollaston) (Hymenoptera: Scelionidae) and Ooencyrtus telenomicida (Vassiliev) (Hymenoptera: Encyrtidae), is dominated by O. telenomicida. In this article we investigated the role played by the ovipositing $O$. telenomicida female in the suppression of a T. basalis competitor. Laboratory experiments were conducted by allowing an O. telenomicida female to puncture the eggs of Nezara viridula (L.) (Heteroptera: Pentatomidae) with her ovipositor (= no oviposition) or to parasitize them. The results show that $O$. telenomicida relies on some physiological mechanisms to mediate its interspecific intrinsic competition with $T$. basalis. In fact, the emergence of $T$. basalis was strongly reduced in host eggs that were parasitized either before or after being punctured by $O$. telenomicida at fixed time intervals $(5,15,30$, or $45 \mathrm{~h})$. The low percentage of emergence of $T$. basalis (ranging from approximately 4-20\%) was a consequence of the delay and growth rate reduction of larval development. Furthermore, the percentage of eclosion of $N$. viridula nymphs was negatively affected by the O. telenomicida female's punctures (96\% from healthy host eggs, $4 \%$ from punctured host eggs). Host eggs punctured or oviposited in by $O$. telenomicida showed alterations in the ooplasm including some melanized-like areas near the hole made with the ovipositor; such alterations indicate that the adult parasitoid releases substances that affect the host eggs survival. These results suggest that the $O$. telenomicida female influences both the physiological interspecific parasitoid-parasitoid interaction, as well as the host-parasitoid interaction, providing, for the first time in egg parasitoids, evidence that physiological suppression of some competitive egg parasitoids is mediated by the ovipositing female.
\end{abstract}

\section{Introduction}

Multiple parasitoids can coexist on a single host species (Hawkins, 1994). Coexisting species can often compete in the field especially when the host density is scarce. Competition between coexisting parasitoid species can be divided into extrinsic and intrinsic competition (Zwolfer, 1971; De Moraes et al., 1999). Extrinsic competition refers to the general interactions occurring between adults searching for hosts, whereas intrinsic competition refers to the inter-

${ }^{*}$ Correspondence: Ezio Peri, Dipartimento DEMETRA, Università degli Studi di Palermo, viale delle Scienze, Palermo 90128, Italy.

E-mail: ezio.peri@unipa.it actions occurring between larvae developing within the same host (multiparasitism sensu Mackauer, 1990). In the case of intrinsic competition, supernumerary larvae have to compete quickly to avoid losing some of the limited resources resulting in insufficient food intake for both competitors (Godfray, 1994). In western Sicily, a 3-year collection (2008-2010) of sentinel and naturally laid egg masses of the southern green stink bug, Nezara viridula (L.) (Heteroptera: Pentatomidae), revealed that two solitary parasitoids, Trissolcus basalis (Wollaston) (Hymenoptera: Scelionidae) and Ooencyrtus telenomicida (Vassiliev) (Hymenoptera: Encyrtidae), can exploit the same egg mass in about $25 \%$ of the total collected samples (Peri et al., 2011). These parasitoid species differ in their host location 
and larval competitive abilities and a trade-off between extrinsic and intrinsic competition may be important for species coexistence (Cusumano et al., 2011). In fact, T. basalis is able to exploit several chemical cues to locate $N$. viridula eggs including volatile and contact cues emitted from adult bugs and synomones induced by feeding and oviposition activities of the host (Colazza et al., 1999, 2004; Peri et al., 2006). In contrast, O. telenomicida eavesdrops the volatile sex pheromone which is emitted by $N$. viridula virgin males (Peri et al., 2011). However, when multiparasitism takes place, the inferior host location efficiency of $O$. telenomicida is counterbalanced by its superior larval survival. In fact, in laboratory experiments, $O$. telenomicida outcompetes $T$. basalis regardless whether ovipositions occur simultaneously or, in sequential exploitation, which species oviposits first (Cusumano et al., 2011).

The two main mechanisms involved in elimination of supernumerary parasitoids are physical attack and/or physiological suppression. The elimination of competitors by physical attack has been extensively observed in solitary parasitoids (Salt, 1961; Vinson, 1972; Chow \& Mackauer, 1984, 1986; Mackauer, 1990; Quicke, 1997). In fact, their first instars are usually provided with large mandibles. On the contrary, larvae of gregarious parasitoids are generally equipped with smaller mandibles; consequently, solitary parasitoids may have an advantage when competing with gregarious ones (Laing \& Corrigan, 1987; Kfir \& van Hamburg, 1988) even if exceptions have also been reported (Boivin \& van Baaren, 2000; Pexton \& Mayhew, 2001). A similar situation often occurs when the time interval between ovipositions is such that one of the competitors has become a second instar and the other is a first instar. In fact, the falcate mandibles are lost when larvae molt into a second instar resulting in organs only adapted for feeding and, consequently, this larval instar is usually not able to injure the first instar (Chow \& Mackauer, 1986; van Baaren et al., 1995). Interestingly, in the ectoparasitoid Pachycrepoideus vindemmiae Rondani, during intraspecific interactions, the older larvae can kill the younger ones (Goubault et al., 2003). Wounds inflicted as a consequence of fights became melanized and are readily seen on dead individuals (Fisher, 1961; Salt, 1961; Harvey \& Partridge, 1987; Mackauer, 1990).

Physiological suppression between parasitoid species involves multiple mechanisms, including toxic factors, anoxia induction, and nutrient removal (Spencer, 1926; Fisher, 1963; Hagvar, 1988; Vinson \& Hegazi, 1998; Uka et al., 2006; Bai et al., 2011). Often dead parasitoid eggs or larvae lacking any marks of a physical attack constitute the only available evidence of physiological suppression so that researches are forced to assume that a suppressive factor must be involved. Furthermore, first instars with large mandibles can employ other mechanisms than physical attack to eliminate rivals, such as physiological suppression (Strand, 1986; Mackauer, 1990).

In our system the mechanism adopted by $O$. telenomicida to outcompete T. basalis is still unexplored. However, morphological observations suggested that physical attack may not be the main outcompeting mechanism involved. In fact, the first instar of O. telenomicida has minute mandibles compared to the large sickle-shaped mandibles present in the first instar of T. basalis. Furthermore, T. basalis has a ring of 10 thoracic hairs that allow the larva to move in the host ooplasm 'seeking' for a competitor (Volkoff \& Colazza, 1992). In contrast, the O. telenomicida larva is attached to the host chorion through its respiratory stalk and this mobility constraint gives it a physical disadvantage. Although it has been reported in endoparasitoids that the ovipositing female can physically injure the competitor's offspring through ovicide or infanticide (Netting \& Hunter, 2000; Collier et al., 2007; Tena et al., 2008), there is a lack of studies focusing on the possible role of the ovipositing female in mediating the interspecific intrinsic competition through physiological suppression especially in oophagous insects (Mackauer, 1990). During oviposition, a wasp female could take over an already parasitized host and make it suitable for the development of her own offspring by injecting toxic substances for the competing parasitoid (Mackauer, 1990). Also, a wasp female can inject factors that influence the metabolism of their hosts preparing them for the survival of her progeny (Vinson, 1977, 1990; Stoltz \& Vinson, 1979; Vinson \& Iwantsch, 1980; Beckege, 1985; Dushay \& Beckage, 1993). In O. telenomicida possible evidence of a physiological host-parasitoid interaction is suggested by the alteration of the ooplasm of $N$. viridula eggs. In fact, as earlier noted by Catalan \& Verdu (2005), oviposition of O. telenomicida into $N$. viridula hosts is associated with a melanized-like area, visible through the host's translucent chorion, which is localized around the parasitoid egg stalk protruding from the host egg. Such ooplasm alteration does not simply result from a mechanical damage caused by the parasitoid female with the ovipositor, as it does not occur on stink bug eggs that were mechanically damaged with the tip of a tungsten probe simulating parasitoid punctures (Koppel et al., 2011). However, it is unclear whether the ooplasm alteration is due to the action of the ovipositing female, her egg, or to a substance released by the interaction between the parasitoid and the injured host egg. Therefore, investigating the role of $O$. telenomicida in mediating the competition with $T$. basalis eggs or larvae within the $N$. viridula egg appeared to be an interesting question.

The oviposition behavior of $O$. telenomicida is a complex sequence that includes drumming, drilling, and 
concurrent host feeding (sensu Jervis \& Kidd, 1986). During the host feeding, the female punctures the host with her ovipositor and feeds on the small droplet of ooplasm emerging from the wound repeating the drilling-host feeding sequence from 12 to 36 times before she lays the egg (A Cusumano, unpubl.). The purpose of this study was to test the ability of $O$. telenomicida females through punctures and host feeding to mediate the parasitoid-parasitoid (T. basalis-O. telenomicida) and host-parasitoid (N. viridula-O. telenomicida) interaction. In the first experiment we investigated whether or not the wasp female can affect the percentage of emergence of $T$. basalis according to the order of the parasitoid species exposures, and the time interval between exposures. Then we investigated in detail the stage at which the development of $T$. basalis is impaired by $O$. telenomicida female behavior. Finally, we investigated whether or not the melanization-like process that occurs when $N$. viridula eggs are parasitized by O. telenomicida is due to the action of the wasp female during the puncture and host feeding behavior.

\section{Materials and methods}

\section{Insect rearing}

The N. viridula colony, established from material collected from cultivated and uncultivated fields around Palermo, Italy $\left(38^{\circ} 03^{\prime} 57^{\prime \prime} \mathrm{N}, 13^{\circ} 28^{\prime} 10^{\prime \prime} \mathrm{E}\right)$, was reared in wooden cages $(50 \times 30 \times 35 \mathrm{~cm})$, provided with mesh-covered holes $(5 \cdot \mathrm{cm}$ diameter $)$, in a climatic chamber $\left(24 \pm 1{ }^{\circ} \mathrm{C}\right.$, $70 \pm 5 \%$ r.h., and L16:D8 photoperiod), and fed with a diet of raw sunflower seeds, cabbages, cauliflowers, and beans. Food was changed every 2-3 days, and separate cages were used for nymphs and adults. Paper towels were hung inside each adult cage as ovipositional substrate. Egg masses were collected daily and used to maintain the colony which was also regularly augmented with bugs collected in fields around Palermo $\left(38^{\circ} 03^{\prime} 57^{\prime \prime} \mathrm{N}\right.$, $\left.13^{\circ} 28^{\prime} 10^{\prime \prime} \mathrm{E}\right)$.

The T. basalis and the O. telenomicida colonies were originally collected from wasps emerging from sentinel and/or naturally laid $N$. viridula egg masses in tomato crops located around Palermo $\left(37^{\circ} 44^{\prime} 23^{\prime \prime} \mathrm{N}-13^{\circ} 08^{\prime} 27^{\prime \prime} \mathrm{E}\right)$. Adult parasitoids were reared, separately, in 16-ml glass tubes, fed honey water solution, and kept in an incubator (L16:D8 photoperiod, $24 \pm 2{ }^{\circ} \mathrm{C}$, and $80 \pm 5 \%$ r.h.). Daily collected $N$. viridula egg masses were exposed to parasitoids for $48 \mathrm{~h}$, then they were removed and stored in another tube for incubation. After emergence, male and female parasitoids were kept together to allow for mating. In all experiments, female wasps of both species were mated, naïve concerning host oviposition, and 4-5 days old. This time window has been selected to use wasps of both species at the same age and ready to lay eggs, as T. basalis is pro-ovigenic and O. telenomicida is synovigenic. About $24 \mathrm{~h}$ before the assays, female wasps were isolated in small vials $(1.5 \times 5 \mathrm{~cm})$ with a drop of honey water solution, and kept in the bioassays room to acclimate.

\section{Order of parasitoid species exposure and the time interval between exposures}

The objective of the experiment was to investigate whether or not the sequence of the species exposure and the time interval between exposures play a role in the emergence (\%) of T. basalis. A single egg of N. viridula, detached from a 24 h-old egg mass, was fastened onto a piece of Parafilm $^{\text {TM }}$ (Pechiney Plastic Packaging, Chicago, IL, USA) inside a plastic 4-cm Petri dish and exposed to both parasitoid species to obtain the following two treatments: (1) 'Ot then Tb': egg punctured by O. telenomici$d a$, i.e., the female was removed after 10 drilling-host feeding bouts without egg deposition, and then parasitized by T. basalis at fixed intervals; (2) 'Tb then Ot': egg parasitized by $T$. basalis and subsequently punctured by O. telenomicida at fixed intervals. We decided to remove the $O$. telenomicida female after 10 drilling-host feeding bouts to interrupt the oviposition process just before the egg laying step (A Cusumano, unpubl.). The time intervals between exposures were $5,15,30$, or $45 \mathrm{~h}$, starting from the removal of the first female. As a control, eggs parasitized by T. basalis (non-punctured host eggs) were used. After the exposures, $N$. viridula eggs were stored in a climatic chamber $\left(24 \pm 2{ }^{\circ} \mathrm{C}\right.$ and $80 \pm 5 \%$ r.h. $)$ until emergence of $T$. basalis. For each of four time intervals and for each treatment, 25 replicates were performed.

\section{Developmental stage of Trissolcus basalis impaired by Ooencyrtus telenomicida female}

The purpose of the experiment was to investigate the effects of $O$. telenomicida oviposition behavior on T. basalis immature development. Two eggs of $N$. viridula, detached from a 24-h-old egg mass, were fastened onto a piece of Parafilm ${ }^{\mathrm{TM}}$ inside a plastic 4-cm Petri dish and exposed to a single T. basalis female. After both eggs were parasitized, $T$. basalis was removed, and the eggs were exposed to a single female of $O$. telenomicida, which was removed soon after she punctured and performed 10 drilling-host feeding bouts in one of the two eggs. After the treatments, the eggs (one parasitized by T. basalis, and the other parasitized by T. basalis and punctured by O. telenomicida) were stored in an incubator $\left(24 \pm 2{ }^{\circ} \mathrm{C}, 80 \pm 5 \%\right.$ r.h. $)$ until dissections were carried out to investigate the comparative development of T. basalis larvae. Eggs were dissected at 20, 45, or $70 \mathrm{~h}$ after $T$. basalis parasitization. These intervals are 
representative of the T. basalis immature development from hatching in N. viridula eggs until the mature larva consumes the host yolk (Volkoff \& Colazza, 1992). Dissections were performed with entomological needles and forceps by gently removing the operculum and flushing out all the egg content in a drop of Ringer solution. Observations were carried out under a stereomicroscope (Olympus SZX12 with a WHS15X/16 ocular and a De Plapo 1.2 XPF lense; Olympus, Tokyo, Japan) equipped with a calibrated cross-hair micrometer. For each of the development times, 10 hosts for both treatments were dissected and the distance between the tip of the cephalothoracic region and the end of the caudal region was taken as a measure of larval body length.

\section{Host-parasitoid interactions within a host egg}

The purpose of this experiment was to investigate the effects of $O$. telenomicida oviposition behavior on the development of $N$. viridula eggs. A single egg of N. viridula, detached from a 24-h-old egg mass, was fastened onto a piece of Parafilm ${ }^{\mathrm{TM}}$ inside a plastic 4-cm Petri dish, and exposed to an $O$. telenomicida female to obtain: a punctured host, i.e., a host in which O. telenomicida has performed 10 drilling-host feeding bouts (a dot of acrylic paint was put near the puncture to mark the hole), and a parasitized host, i.e., a host in which $O$. telenomicida has laid an egg. Preliminary experiments have shown that the acrylic paint did not induce any negative effect on the host development as well as on the eclosion of $N$. viridula eggs (A Cusumano, unpubl.). As control, healthy hosts were used, i.e., host eggs not exposed to O. telenomicida. The experiment was replicated $35 \times$ for all host types. All eggs were stored in a climatic chamber $\left(24 \pm 2{ }^{\circ} \mathrm{C}, 80 \pm 5 \%\right.$ r.h.). Twenty-five eggs were maintained until eclosion, 10 eggs were regularly observed to determine the presence/absence of a melanization-like area. Parasitized hosts in which such an area was found, were dissected in Ringer's physiological saline under a stereomicroscope as described in the previous experiment to document the relationship between the melanization and the developing egg of the parasitoid.

\section{Image treatment and data analysis}

Optical micrographs were taken using a Canon EOS Digital Rebel Xt (Canon, Tokyo, Japan) on an Olympus microscope to document: (1) the development of T. basalis in both punctured and non-punctured hosts, (2) the occurrence of melanization-like areas on host types that were punctured or parasitized by $O$. telenomicida, and (3) the relationship between melanization-like area and the developing egg of O. telenomicida. Emergence (\%) of T. basalis was analyzed by $\chi^{2}$ tests, whereas body lengths of $T$. basalis larvae were compared with a Mann-Whitney U-test. All data were analyzed using STATISTICA 7 software (StatSoft, 2001).

\section{Results}

Order of parasitoid species exposure and the time interval between exposures

The percentage of emergence of $T$. basalis was dependent on the puncture made by $O$. telenomicida $\left(\chi^{2}=155.40\right.$, d.f. $=8, \mathrm{P}<0.001)$. In particular, parasitoid emergence was significantly different between punctured and non-punctured hosts, regardless of the order of species exposure and the time interval between exploitations ( $\mathrm{Tb}$ then $\mathrm{Ot}, 5 \mathrm{~h}$ : $\chi^{2}=19.40, \quad 15 \mathrm{~h}: \chi^{2}=23.08,30 \mathrm{~h}: \chi^{2}=17.68,45 \mathrm{~h}:$ $\chi^{2}=21.20$; Ot then Tb, $5 \mathrm{~h}: \chi^{2}=19.40,15 \mathrm{~h}: \chi^{2}=21.20$, 30 h: $\chi^{2}=17.68,45$ h: $\chi^{2}=16.04$; all d.f. $=1, \mathrm{P}<0.001$ ) (Figure 1). The percentage of emergence of T. basalis was not significantly different, regardless whether the puncture of $O$. telenomicida occurred before or after parasitization by $T$. basalis $\left(\chi^{2}=0.97\right.$, d.f. $\left.=3, P=0.81\right)$. In all bioassays it was found that, when $T$. basalis developed in host eggs punctured by $O$. telenomicida, only few $T$. basalis emerged [lowest percentage: $\mathrm{Tb}$ then Ot, $4 \pm 3.2 \%$ (15 h between exposures); highest percentage: $\mathrm{Ot}$ then $\mathrm{Tb}$, $20 \pm 8.0 \%$ ( $45 \mathrm{~h}$ between exposures)]; most $T$. basalis adults died. On the contrary, when T. basalis developed in non-punctured host eggs most of the parasitoids emerged (96 $\pm 3.9 \%)$ (Figure 1).

\section{Developmental stage of Trissolcus basalis impaired by Ooencyrtus telenomicida female}

Larvae of T. basalis were found in all the dissected host eggs. Larvae obtained from dissections at $20 \mathrm{~h}$ had a similar body length, regardless whether they have developed in hosts punctured by $O$. telenomicida or not $(\mathrm{Z}=-0.466$, $\mathrm{P}=0.64)$ (Figure $2 \mathrm{~A})$. Larvae obtained by dissections at $45 \mathrm{~h}$ were significantly smaller when they developed in punctured hosts than in non-punctured hosts $(45 \mathrm{~h}$ : $\mathrm{Z}=3.797, \mathrm{P}<0.001$ ) (Figure 2A). In fact, after $45 \mathrm{~h}$ the body length of larvae that developed in punctured hosts was $0.30 \pm 0.022 \mathrm{~mm}$ (mean $\pm \mathrm{SEM}$ ), whereas the body length of those larvae that developed in non-punctured hosts was $0.60 \pm 0.003 \mathrm{~mm}$ (Figure 2B). Larvae obtained from dissections at $70 \mathrm{~h}$ were found to have reached different instars: larvae from non-punctured hosts had molted to the second instar (body length $=1.15 \pm 0.029 \mathrm{~mm}$ ), whereas larvae from punctured hosts were still first instar (body length $=0.37 \pm 0.050 \mathrm{~mm}$ ) (Figure 2C). In non-punctured hosts, the T. basalis larvae accumulated abundant yellow material in their guts. In contrast, all the T. basalis larvae developing in punctured hosts displayed melanization of their total body. 


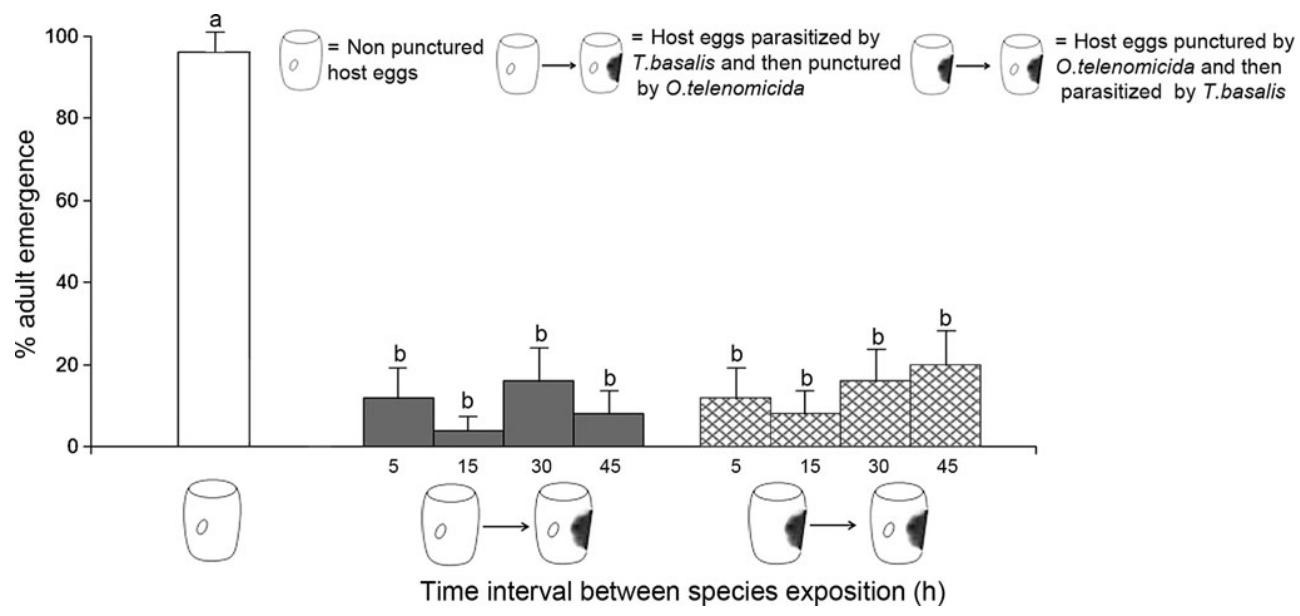

Figure 1 Mean (+ SEM) emergence rate (\%) of Trissolcus basalis from host eggs exposed to both T. basalis and Ooencyrtus telenomicida in a different order and at different time intervals. Host eggs were first parasitized by T. basalis and then punctured by O. telenomicida (gray bars), or the other way around (cross bars). Time intervals were 5, 15, 30, or $45 \mathrm{~h}$. The emergence of $T$. basalis from non-punctured host eggs is represented by the white bar. Means capped by different letters are significantly different $\left(\chi^{2}\right.$ test: $\left.\mathrm{P}<0.05\right)$.
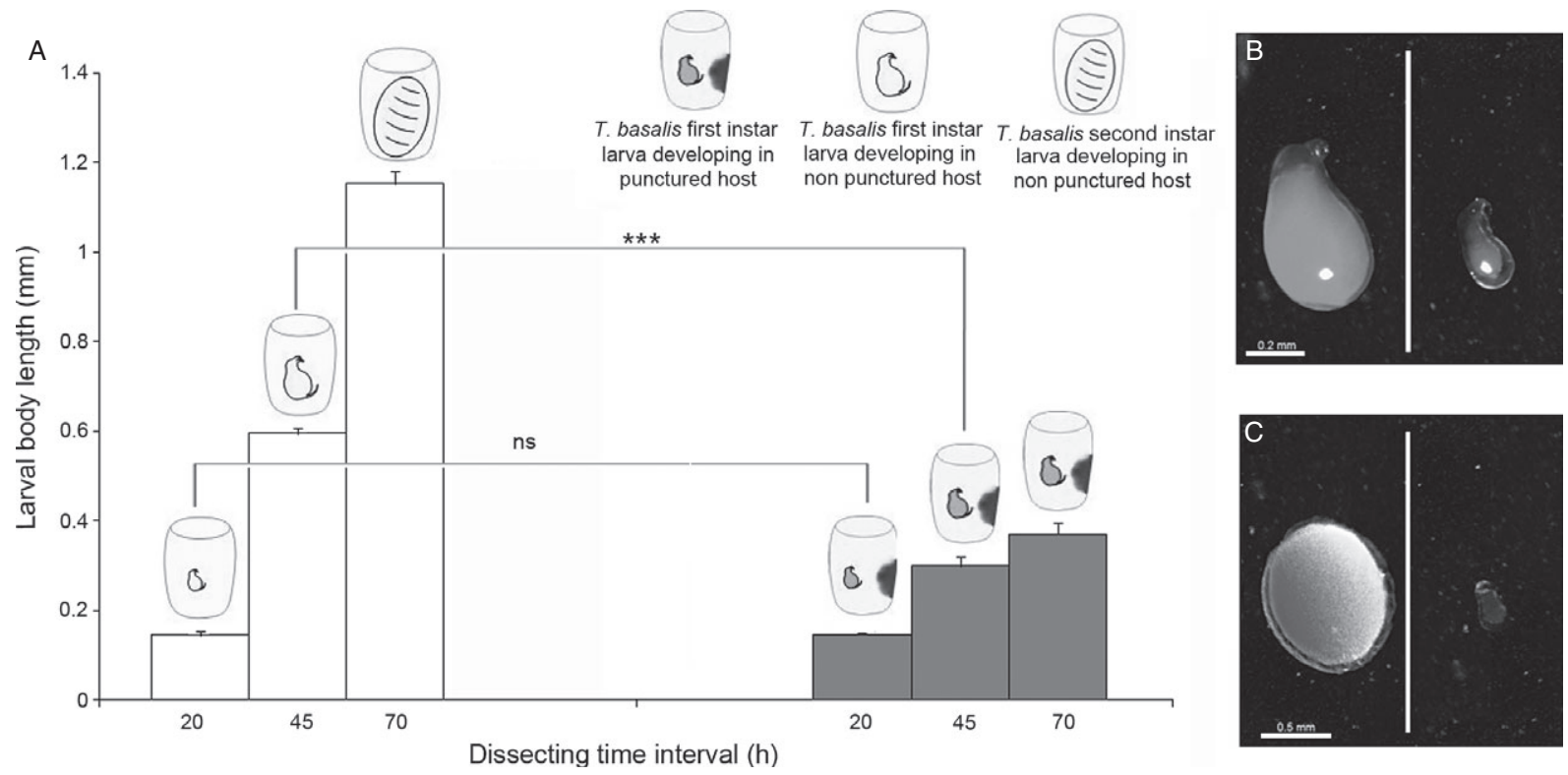

Figure 2 (A) Mean ( \pm SEM) body length ( $\mathrm{mm}$ ) of Trissolcus basalis larvae obtained by dissecting at fixed times host eggs parasitized by T. basalis (non-punctured; white bars), or parasitized by T. basalis and punctured by Ooencyrtus telenomicida (punctured; dark bars). Eggs were dissected at 20, 45, or $70 \mathrm{~h}$ after T. basalis parasitization. Body lengths of larvae obtained at the 20 and $45 \mathrm{~h}$ dissection time intervals were analyzed by Mann-Whitney U test; ns, not significant, ${ }^{* *} \mathrm{P}<0.001$. Data at $70 \mathrm{~h}$ were not analyzed because in punctured host eggs, first instar T. basalis never molted. (B) Optical micrographs of T. basalis larvae developing in non-punctured (left) or in punctured (right) host eggs by $O$. telenomicida female after $45 \mathrm{~h}$ development, and (C) after $70 \mathrm{~h}$.

\section{Host-parasitoid interactions within a host egg}

The parasitoid puncture affected egg emergence of $N$. viridula nymphs, because stink bug nymphs were recorded from $96 \pm 8.5 \%$ of healthy, and from $4 \pm 2.0 \%$ of punctured hosts. No emergence of stink bug nymphs was obtained from parasitized hosts. Punctured hosts showed a melanized-like area around the puncture made by the adult female through the host chorion (Figure 3A). Similarly, hosts parasitized by $O$. telenomicida displayed a melanized-like area surrounding the parasitoid respiratory 

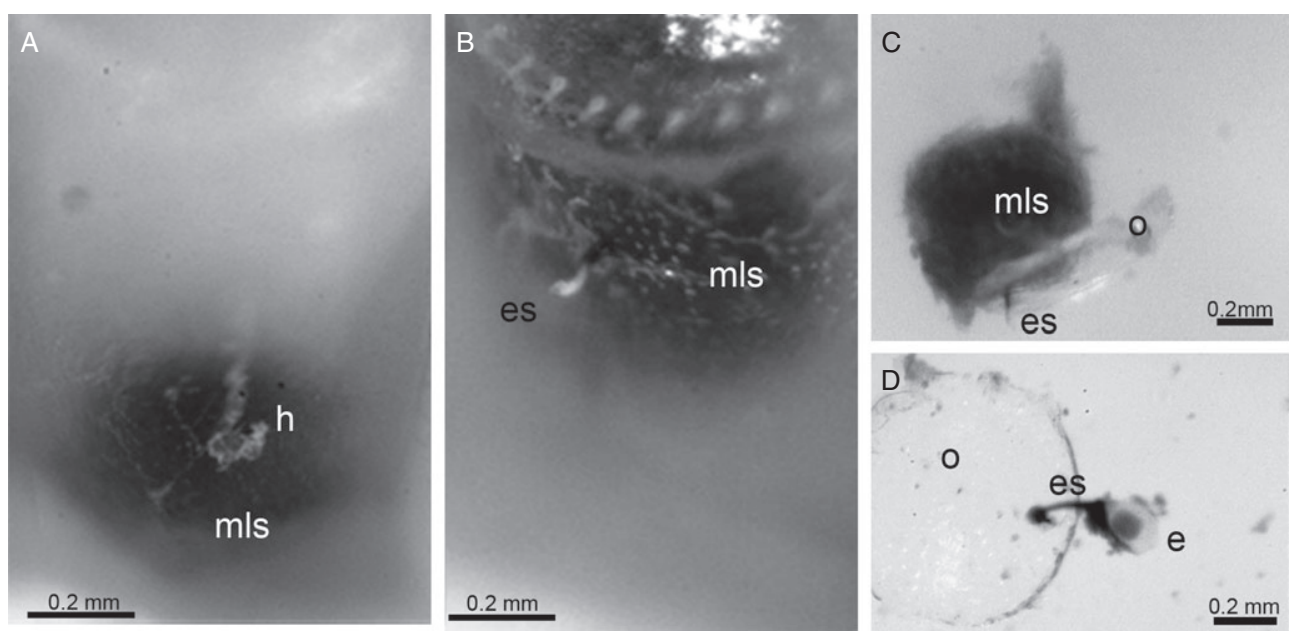

Figure 3 (A) Melanized-like area in Nezara viridula eggs attacked by Ooencyrtus telenomicida female localized around the hole in a punctured host egg, and (B) around the egg stalk in a parasitized host egg. (C) After $24 \mathrm{~h}$ the melanized-like substance envelops the parasitoid egg, which (D) appears translucent once the melanized-like substance is removed ad hoc. e, O. telenomicida egg; es, egg stalk; h, hole; mls, melanized-like substance; o, operculum.

stalk protruding from the host; part of the egg stalk closer to the chorion was also found melanized (Figure 3B). The developing egg of $O$. telenomicida was found completely immersed inside a melanized-like substance that was different in consistency and color from the host yolk (Figure $3 \mathrm{C}$ and $\mathrm{D}$ ).

\section{Discussion}

The results presented in this study provide evidence that the ovipositing $O$. telenomicida relies on a physiological mechanism to mediate interspecific intrinsic competition. In fact, regardless of whether host eggs were first parasitized by $T$. basalis and then punctured by $O$. telenomicida, or vice versa, the percentage of $T$. basalis that emerges is strongly reduced. On the basis of these findings it is possible to exclude any mechanical damage leading to ovicide or infanticide that the O. telenomicida female may cause to its competitor while inserting several times the ovipositor into the host egg. When O. telenomicida punctures $N$. viridula eggs containing a T. basalis egg, the T. basalis eggs always hatch, and in few cases adults emerge. However, T. basalis larvae display a reduced growth rate and exhibit development delays compared to the larvae that developed in non-punctured host eggs. In fact, the results of host egg dissected $70 \mathrm{~h}$ after T. basalis parasitization revealed that non-punctured host eggs contain T. basalis second instars, whereas punctured hosts contain first instars. These results strongly support the possibility that competition between T. basalis and O. telenomicida is affected by factor(s) injected by $O$. telenomicida female prior to the egg deposition, which likely makes the ooplasm unsuitable for T. basalis larval development. To the best of our knowledge, this is the first evidence in egg parasitoids that the ovipositing female can mediate physiological suppression. The superior intrinsic ability of Ooencyrtus species competing with Trissolcus or Telenomus species have been already highlighted, but in neither of these species has the mechanisms of suppression been elucidated (Laraichi, 1978; Conde \& Rabinovich, 1979; Lee, 1979; Sjaarda, 1989).

The physiological suppression mechanisms that may be mediated by the ovipositing female have been shown or hypothesized in a few larval parasitoids. For example, there is the case of the intrinsic competitive interaction between aphid parasitoids of the genera Ephedrus and Aphidius (Hagvar, 1988; Mackauer, 1990). Hagvar (1988) reported that the eggs of Aphidius matricariae Haliday failed to hatch even when an egg of the dominant competitor, Ephedrus cerasicola Stary, had not yet hatched suggesting that the suppression was either due to factors injected by the ovipositing female of E. cerasicola or released from her egg. Further, Mackauer (1990) stated that the eggs of Aphidius smithii Sharma \& Subba Rao were killed within 28-30 h after Ephedrus californicus Baker had punctured the host without ovipositing. However, the effect of the physiological suppression described for the system Ephedrus spp.-Aphidius spp. is different from that occurring in the system Trissolcus spp.-Ooencyrtus spp. Further, in the case reported herein the ovipositing female of $O$. telenomicida seems not to affect the eggs of its competitor, which hatched, but instead impacts the larvae of $T$. basalis which were small and dark. In addition, when $N$. viridula eggs 
contained a first instar of T. basalis and were subsequently punctured by $O$. telenomicida, it was found that T. basalis suffered high mortality and only few adults emerged. Our results are more similar to the recent findings of Bai et al. (2011) about the intrinsic competition between Cotesia vestalis (Haliday) and Oomyzus sokolowskii Kurdjumov, two endoparasitoids of the diamondback moth, Plutella xylostella (L.). They showed that the sterilized female of the superior intrinsic competitor, C. vestalis, injects waspassociated factors capable of affecting the development of O. sokolowskii larvae within the host.

The influence of the ovipositing female in mediating interspecific intrinsic competition via physiological suppression may be underestimated due to the lack of experiments specifically developed to test this phenomenon (Conde \& Rabinovich, 1979; Sjaarda, 1989; De Moraes et al., 1999; De Moraes \& Mescher, 2005; Mucheru et al., 2009). Nevertheless, more experimental work based on the manipulation of the oviposition behavior or based on the oviposition of sterilized female wasps is required to clarify physiological suppression in insect parasitoids. In addition to the parasitoid-parasitoid interaction, the ovipositing female of $O$. telenomicida also plays a role in the host-parasitoid interaction. In fact, the alteration of the host ooplasm displayed in N. viridula eggs appears to be triggered by substances probably injected by the adult females and not released by their eggs, given that host yolk modifications and the production of a melanizedlike substance were observed when wasp females were interrupted prior to laying eggs. The fact that $T$. basalis mortality was similar regardless whether O. telenomicida punctured the host egg before or after T. basalis oviposition, seems to suggest that $O$. telenomicida injects factor(s) to prepare the host for their offspring development, and which also indirectly affects the interspecific competitor's larvae. The evidence that hosts punctured by an $O$. telenomicida female die further supports this hypothesis. Interestingly enough, dissections of $N$. viridula hosts parasitized by $O$. telenomicida showed that the parasitoid eggs are enveloped in a melanized-like substance. Early morphological studies of Ooencyrtus species attacking pentatomid or coreid hosts did not report any melanization apart from the blackening of the egg stalk which occurs few hours after the parasitoid egg has been laid (Maple, 1937; Laraichi, 1977; Matterson, 1981). Interestingly, melanization and encapsulation have been recently reported in the encyrtid Avetianella longoi Siscaro, an egg parasitoid of Phoracantha recurva Newman, but in this case the melanization process aims at killing the parasitoid egg (Reed et al., 2007).

In conclusion, our results clarify the role of the O. telenomicida ovipositing female in mediating the intrinsic competition with the competitor, T. basalis, and the host, $N$. viridula. However, it would be interesting to identify the nature of the factors that induce the melanized-like area, and their origin, as it cannot be excluded that they could be released from the salivary glands of the ovipositing female during host feeding, or other factors.

\section{Acknowledgements}

The authors would like to thank Freder Medina (Texas A\&M University) for his technical help in performing bioassays, and Anne-Natalie Volkoff (INRA) for her critical comments on an early version of this manuscript. Funding for this work was provided by 'Progetti di Ricerca di Interesse Nazionale - Cofinanziamento 2007' entitled 'Enhancing foraging behavior of insect egg parasitoids: the role of volatile organic compounds and epicuticular layers of plants', chaired by Prof. Stefano Colazza.

\section{References}

van Baaren J, Boivin G \& Nenon JP (1995) Intraspecific hyperparasitism in a primary hymenopteran parasitoid. Behavioural Ecology and Sociobiology 36: 237-242.

Bai SF, Li X, Chen XX, Cheng JA \& He JH (2011) Interspecific competition between two endoparasitoids Cotesia vestalis (Hymenoptera: Braconidae) and Oomyzus sokolowskii (Hymenoptera: Eulophidae). Archives of Insect Biochemistry and Physiology 76: 156-167.

Beckage NE (1985) Endocrine interactions between endoparasitic insects and their hosts. Annual Review of Entomology 30: 371413.

Boivin G \& van Baaren J (2000) The role of larval aggression and mobility in the transition between solitary and gregarious development in parasitoid wasps. Ecology Letters 3: 469-474.

Catalan J \& Verdu MJ (2005) Evaluacion de dos parasitoides de huevos de Nezara viridula. Boletín de Sanidad Vegetal Plagas 3: 187-197. (in Spanish)

Chow FJ \& Mackauer M (1984) Inter and intra-specific larval competition in Aphidious smithi and Praon pequodorum (Hymenoptera: Aphididae). Canadian Entomologist 116: 1097-1107.

Chow FJ \& Mackauer M (1986) Host discrimination and larval competition in the aphid parasite Ephredrus californicus. Entomologia Experimentalis et Applicata 41: 243-254.

Colazza S, Salerno G \& Wajnberg E (1999) Volatile and contact chemicals released by Nezara viridula (Heteroptera: Pentatomidae) have a kairomonal effect on the egg parasitoid Trissolcus basalis (Hymenoptera: Scelionidae). Biological Control 16: 310-317.

Colazza S, Fucarino A, Peri E, Salerno G, Conti E \& Bin F (2004) Insect oviposition induces volatile emission in herbaceous plant that attracts egg parasitoids. Journal of Experimental Biology 207: 47-53. 
Collier TR, Hunter MS \& Kelly SE (2007) Heterospecific ovicide influences the outcome of competition between two endoparasitoids, Encarsia formosa and Encarsia luteola. Ecological Entomology 32: 70-75.

Conde JE \& Rabinovich JE (1979) Larval competition between Telenomus costalima (Hymenoptera: Scelionidae) and Ooencyrtus trinidadensis venatorius (Hymenoptera: Encyrtidae) after simultaneous oviposition in Rhodnius prolixus eggs (Hemiptera: Reduviidae). Journal of Medical Entomology 16: 428-431.

Cusumano A, Peri E, Vinson SB \& Colazza S (2011) Intraguild interactions between two egg parasitoids exploring host patches. BioControl 56: 173-184.

De Moraes CM \& Mescher M (2005) Intrinsic competition between larval parasitoids with different degrees of host specificity. Ecological Entomology 30: 564-570.

De Moraes CM, Cortesero AM, Stapel JO \& Lewis WJ (1999) Intrinsic and extrinsic competition between two larval parasitoids of Heliothis virescens. Ecological Entomology 24: 402410.

Dushay MS \& Beckage NE (1993) Dose-dependent separation of Cotesia congregata-associated polydnavirus effects on Manduca sexta larval development and immunity. Journal of Insect Physiology 39: 1029-1040.

Fisher RC (1961) A study in insect multiparasitism II. The mechanism and control of competition for possession of the host. Journal of Experimental Biology 38: 605-628.

Fisher RC (1963) Oxygen requirements and the physiological suppression of supernumerary insect parasitoids. Journal of Experimental Biology 40: 531-540.

Godfray HCJ (1994) Parasitoids: Behavioral and Evolutionary Ecology. Princeton University Press, Princeton, NJ, USA.

Goubault M, Plantegenest M, Poinsot D \& Cortesero AM (2003) Effect of expected offspring survival probability on host selection in a solitary parasitoid. Entomologia Experimentalis et Applicata 109: 123-131.

Hagvar EB (1988) Multiparasitism of the green peach aphid, Myzus persicae: competition in the egg stage between Aphidius matricariae and Ephedrus cerasicola. Entomologia Experimentalis et Applicata 47: 275-282.

Harvey PH \& Partridge L (1987) Murderous mandibles and black holes in hymenopteran wasps. Nature 326: 128-129.

Hawkins BA (1994) Pattern and Process in Host-Parasitoid Interactions. Cambridge University Press, Cambridge, UK.

Jervis MA \& Kidd NAC (1986) Host-feeding strategies in hymenopteran parasitoids. Biological Review 61: 395-434.

Kfir R \& van Hamburg H (1988) Interspecific competition between Telenomus vulletti (Hymenoptera: Scelionidae) and Trichogrammatoidea lutea (Hymenoptera: Trichogrammatidae) parasitizing eggs of the cotton bollworm Heliothis armigera in the laboratory. Environmental Entomology 17: 664-670.

Koppel AL, Herbert DA Jr \& Westbrook EW (2011) Using microscopy to assess chorion structural integrity and parasitoid oviposition sites on stink bug (Hemiptera: Pentatomidae) eggs. Microscopy and Microanalysis 17: 114-117.
Laing JE \& Corrigan JE (1987) Intrinsic competition between the gregarious parasite, Cotesia glomeratus and the solitary parasite, Cotesia rubecula (Hymenoptera: Braconidae) for their host, Artogeia rapae (Lepidoptera: Pieridae). Entomophaga 32: 493-501.

Laraichi M (1977) Contribution to the study of preimaginal growth of Ooencyrtus spp., oophagus parasites of the wheatbug. Annales de la Société Entomologique de France 13: 439452. (in French)

Laraichi M (1978) Étude de la compétition intra- et interspecifique chez les parasites oophages des punaises des blés. Entomophaga 23: 115-120. (in French)

Lee SC (1979) Evaluation of Ooencyrtus submetallicus (Howard) and Trissolcus basalis (Wollaston) as Egg Parasites of Nezara viridula (Linnaeus). PhD Dissertation, Louisiana State University, Baton Rouge, LA, USA.

Mackauer M (1990) Host discrimination and larval competition in solitary endoparasitoids. Critical Issues in Biological Control (ed. by M Mackauer, LE Ehler \& J Roland), pp. 14-62. Intercept, Andover, UK.

Maple JD (1937) The biology of Ooencyrtus johnsonii (Howard), and the role of the egg shell in the respiration of certain encyrtid larvae (Hymenoptera). Annals of Entomological Society of America 30: 123-154.

Matterson PC (1981) Egg parasitoids of hemipteran pests of cowpea in Nigeria and Tanzania, with special reference to Ooencyrtus patriciae Subba Rao (Hymenoptera: Encyrtidae) attacking Clavigralla tomentosicollis Stål (Hemiptera: Coreidae). Bulletin of Entomological Research 71: 547-554.

Mucheru OM, Jiang N, Kongoro J, Bruce AJ \& Schulthess F (2009) Intrinsic competition between two oligophagous parasitoids, Sturmiopsis parasitica and Cotesia sesamiae, attacking the same life stages of lepidopteran cereal stemborers. Entomologia Experimentalis et Applicata 130: 1020.

Netting JF \& Hunter MS (2000) Ovicide in the whitefly parasitoid, Encarsia formosa. Animal Behaviour 60: 217-226.

Peri E, Sole MA, Wajnberg E \& Colazza S (2006) Effect of host kairomones and oviposition experience on the arrestment behavior of an egg parasitoid. Journal of Experimental Biology 209: 3629-3635.

Peri E, Cusumano A, Agrò A \& Colazza S (2011) Behavioral response of the egg parasitoid Ooencyrtus telenomicida to hostrelated chemical cues in a tritrophic perspective. BioControl 56: 163-171.

Pexton JJ \& Mayhew PJ (2001) Immobility: the key to family harmony? Trends in Ecology \& Evolution 16: 7-9.

Quicke DLJ (1997) Parasitic Wasps. Chapman and Hall, London, UK.

Reed DA, Luhring KA, Stafford CA, Hansen KA, Millar JG et al. (2007) Host defensive response against an egg parasitoid involves cellular encapsulation and melanization. Biological Control 41: 214-222.

Salt G (1961) Competition among insect parasitoids. Mechanisms in Biological Competition, Symposia of the Society for Experimental Biology 15: 96-119. 
Sjaarda N (1989) Interactions between the Harlequin Bug Murgantia histrionica Hahn (Hemiptera: Pentatomidae), and the Egg Parasitoids, Trissolcus murgantiae Ashm. (Hymenoptera: Scelionidae) and Ooencyrtus johnsonii How. (Hymenoptera: Encyrtidae): Factors Affecting Patterns of Parasitism in a Southern California Coastal Sage Habitat. PhD Dissertation, University of California, Davis, CA, USA.

Spencer H (1926) Biology of parasites and hyperparsites of aphids. Annals of Entomological Society of America 1: 19-57.

StatSoft (2001) Statistica per Windows, User's Manual. StatSoft Italia, Vigonza, Padova, Italy.

Stoltz DB \& Vinson SB (1979) Viruses and parasitism in insects. Advances in Virus Research 24: 125-171.

Strand MR (1986) The physiological interactions of parasitoids with their hosts and their influence on reproductive strategies. Insect Parasitoids (ed. by J Waage \& D Greathead), pp. 97136. Academic Press, London, UK.

Tena A, Kapranas A, Garcia-Marí F \& Luck RF (2008) Host discrimination, superparasitism and infanticide by a gregarious endoparasitoid. Animal Behaviour 76: 789-799.

Uka D, Hiraoka T \& Iwabuchi K (2006) Physiological suppression of the larval parasitoid Glyptapanteles pallipes by the polyembryonic parasitoid Copidosoma floridanum. Journal of Insect Physiology 52: 1137-1142.

Vinson SB (1972) Competition and host discrimination between two species of tobacco budworm parasitoids. Annals of the Entomological Society of America 65: 229-236.
Vinson SB (1977) Insect host responses against parasitoids and the parasitoids resistance with emphasis on the LepidopteraHymenoptera association. Comparative Pathobiology (ed. by LA Bulla \& TC Cheng), pp. 103-125. Plenum Press, New York, NY, USA.

Vinson SB (1990) How parasitoids deal with the immune system of their host: an overview. Archives of Insect Biochemistry and Physiology 13: 3-27.

Vinson SB \& Hegazi EM (1998) A possible mechanism for the physiological suppression of conspecific eggs and larvae following superparasitism by solitary endoparasitoids. Journal of Insect Physiology 44: 703-712.

Vinson SB \& Iwantsch GF (1980) Host suitability for insect parasitoids. Annual Review of Entomology 25: 397-419.

Volkoff N \& Colazza S (1992) Growth patterns of teratocytes in the immature stages of Trissolcus basalis (Woll.) (Hymenoptera: Scelionidae), an egg parasitoid of Nezara viridula (L.) (Heteroptera: Pentatomidae). International Journal of Insect Morphology and Embryology 21: 323-336.

Zwolfer H (1971) The structure and effect of parasite complexes attacking phytophagous host insects. Dynamics of Populations: Proceedings of the Advanced Study Institute on 'Dynamics and Numbers in Populations' (ed. by PJ den Boer \& GR Gradwell), pp. 405-418. Centre for Agricultural Publishing and Documentation, Wageningen, The Netherlands. 